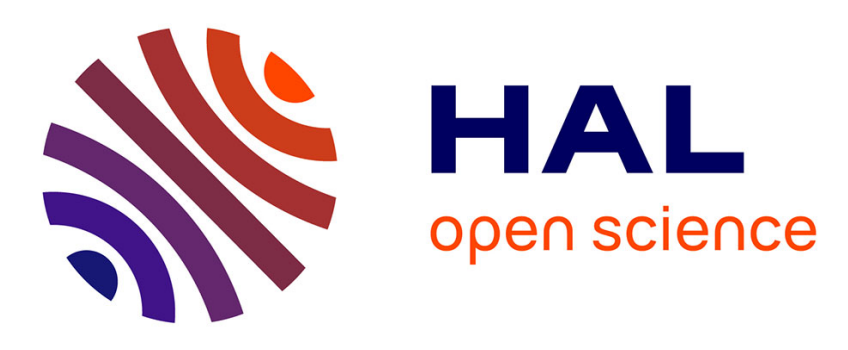

\title{
Synthesis of Versatile Functionalities in Arrangements of 3D Unit-Cells
}

Diego Bermúdez, Carlos Molero, Hervé Legay, Baptiste Palacin, Esteban

Menargues, Raphaël Gillard, M. García-Vigueras

\section{To cite this version:}

Diego Bermúdez, Carlos Molero, Hervé Legay, Baptiste Palacin, Esteban Menargues, et al.. Synthesis of Versatile Functionalities in Arrangements of 3D Unit-Cells. IEEE Conference on Antenna Measurements \& Applications (CAMA), Nov 2021, Antibes Juan-les-Pins, France. hal-03519197

\author{
HAL Id: hal-03519197 \\ https://hal.science/hal-03519197
}

Submitted on 20 Jan 2022

HAL is a multi-disciplinary open access archive for the deposit and dissemination of scientific research documents, whether they are published or not. The documents may come from teaching and research institutions in France or abroad, or from public or private research centers.
L'archive ouverte pluridisciplinaire HAL, est destinée au dépôt et à la diffusion de documents scientifiques de niveau recherche, publiés ou non, émanant des établissements d'enseignement et de recherche français ou étrangers, des laboratoires publics ou privés. 


\section{Synthesis of Versatile Functionalities in Arrangements of 3D Unit-Cells}

\author{
Diego BERMÚDEZ \\ IETR, INSA RENNES, France \\ diego.bermudez-martin@insa- \\ rennes.fr \\ Esteban MENARGUES \\ SWISSto12, Switzerland \\ e.menargues@swissto12.ch
}

\author{
Carlos MOLERO \\ Universidad de Granada, Spain \\ cmoleroj@ugr.es
}

\author{
Hervé LEGAY \\ Thales Alenia Space, France \\ herve.legay@thalesaleniaspace. \\ com
}

\author{
Baptiste PALACIN \\ CNES, France \\ baptiste.palacin@cnes.fr
}

\author{
Raphaël GILLARD \\ IETR, INSA RENNES, France \\ raphael.gillard@insa-rennes.fr
}

\author{
María GARCÍA VIGUERAS \\ IETR, INSA RENNES, France \\ maria.garcia-vigueras@insa-rennes.fr
}

\begin{abstract}
This contribution concentrates on the conception of periodic structures that are built from metallic three-dimensional unit-cells. Such arrangements allow synthesizing diverse functionalities such as polarization conversion, frequency filtering, and impedance matching. In addition, the topologies considered here can be built monolithically employing only metal, therefore providing multiple advantages, such as low insertion losses, high power handling and manufacturing certainty.
\end{abstract}

Keywords- periodic structures, three-dimensional architectures, polarizer, wide angle impedance matching, additive manufacturing

\section{INTRODUCTION}

Periodic screens have been developed already for decades due to their capability to alleviate the complexity of $\mathrm{RF}$ feeds in terms of operation frequency, beam shape, polarization or impedance matching, among others. Classically, such screens are built in two-dimensional stratified or stacked architectures that are commonly implemented through printed-circuit board (PCB) manufacturing and/or by perforation of metal plates $[1,2]$. As illustrative examples, polarizing screens are typically built from arrangements of cascaded meander-line gratings or other elements providing similar RF performance [3, 4].The implementation of screens for Wide Angle Impedance Matching (WAIM) in phased arrays is typically addressed employing simple dielectric slabs or more sophisticated metamaterials and dielectric lenses [5-7].

The advancement of manufacturing technologies has recently encouraged the conception of unit-cells with higher complexity including three-dimensional (3D) geometry. 3D cells provide a large amount of degrees of freedom and they allow for accurate decoupling between vertically and horizontally-polarized excitation. Strong potential is brought by such $3 \mathrm{D}$ geometries, as it is proven by recent publications reporting structures with versatile frequency selective behaviour, absorption bands, enabling polarization control, polarization conversion or focusing [8-20]. Together with those attractive features comes the need for both a new frame to analyse such 3D architectures and specific co-design rules that integrate manufacturing constraints in early steps of the design process.

The present contribution emerges in this context, and illustrates the possibility to synthesize diverse RF functionalities in periodic screens by using innovative $3 \mathrm{D}$ unit-cells. A general conception methodology is employed that consists in building the cells progressively by considering simple circuit models and manufacturing constraints. Several topologies are proposed, that allow to be implemented monolithically through advanced manufacturing techniques. Section II provides the examples of such topologies. Section III illustrates the possibility to synthesize dual-band frequency selective surfaces and converters allowing to induce circular polarization (CP) with orthogonal sense of rotation in two separate bands. Preliminary results are also included concerning the conception of a WAIM. To the best knowledge of these authors, this is the first attempt of a full-metal implementation. Finally, Section IV includes the successful experimental validation of the proposed concepts, based either on electro discharge machining (EDM) and selective laser melting (SLM). The presented results have been obtained in the frame of multiple studies involving the IETR laboratory, industrial partners such as Thales Alenia Space, Thales 3D Morocco, SWISSto12 and the French Centre National d'Etudes Spatiales (CNES).

\section{TOPOLOGIES OF 3D CELLS}

This section presents various topologies of 3D unit-cells that provide dual-polarization capabilities and monolithic manufacturing employing only metal. Such an objective implies facing the challenge of inducing high transmission through screens that are rich in metal, and therefore, may tend to be highly reflective.

The first proposal was presented in [16], and it is here named as Cell \#1 and depicted in Fig. 1(a). This cell consists of a section of length $d$ of rectangular waveguide that is loaded at its input and output walls with perforated screens. The perforations have the shape of folded slots, and there are two pairs of slots per wall, the so-called external and internal resonators. Given their spatial orientation, the external resonators do mostly interact with vertically polarized electric fields, while the internal ones interact with horizontally polarized waves. In order to avoid the appearance of grating lobes, the periodicity of the array is smaller than half a wavelength at the operation frequency. This implies that the rectangular waveguide has an evanescent character, since it operates below the cutoff frequency of the fundamental modes. Regardless its evanescent nature, the unit-cell induces full transmission thanks to the presence of the folded resonators, since their length is comparable to half a wavelength at the operation frequency. 


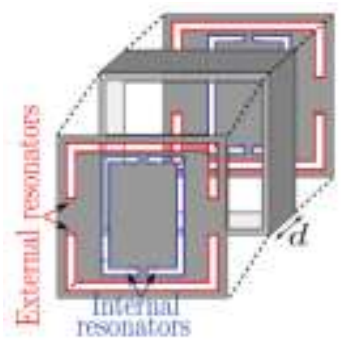

(a)

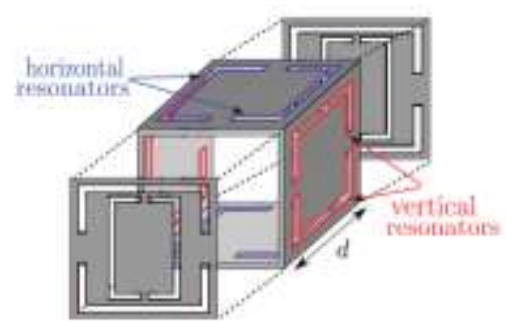

(b)

Fig. 1. 3D unit-cells based on a section of square waveguide perforated with folded resonators. (a) Cell \#1: Perforations are included at the input and output walls of the structure. (b) Cell \#2: Perforations are included at the input, output and lateral walls of the structure.

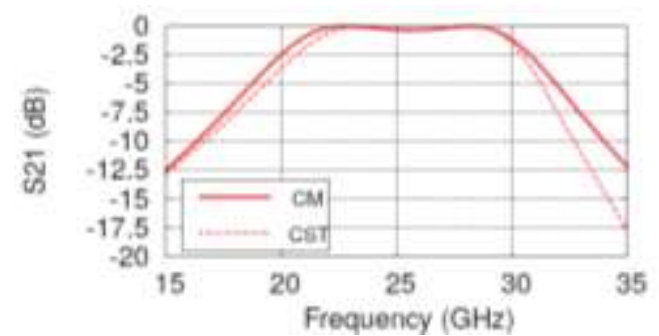

(a)

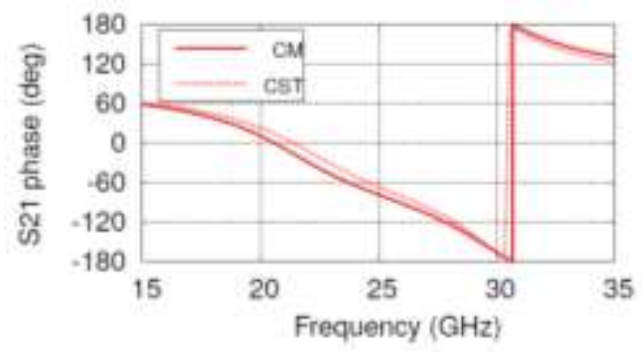

(b)

Fig. 2. Cell \#1: Transmission coefficient, (a) magnitude and (b) phase. (from [16])

The performance of Cell \#1 is illustrated in Fig. 2 considering vertically-polarized excitation. This figure displays results obtained with a full-wave solver (CST) and an equivalent circuit model (CM). More details on the conception of the CM can be found in [16]. As it can be seen in Fig. 2, the magnitude of the S21 coefficient presents a band where the structure is highly transparent to the impinging electromagnetic waves (between $20 \mathrm{GHz}$ and $30 \mathrm{GHz}$, approximately). Two peaks of full transmission can be identified; they are related to the resonance of external resonators. As detailed in [16], this behaviour can be explained in terms of equivalent circuits making an analogy with evanescent filters. The separation between the two peaks of full transmission and the insertion losses within the pass-band can be controlled by modifying the parameter $\mathrm{d}$, which is responsible for the level of coupling between the resonators in the input and output walls of the cell. The phase response of the cell shows a linear dependence with frequency within the magnitude pass-band, which is highly beneficial for polarization control purposes.

The topologies of Cell \#2, \#3 and \#4 evolve naturally from the first one, and they are respectively shown in Fig. 1(b), Fig. 3(a) and Fig. 3(b). Cell \#2 includes perforations in the lateral walls; they interact independently with electric fields with horizontal and vertical polarizations impinging normally [16]. Finally, Cell \#3 and \#4 have open input and output walls, and they count with compound

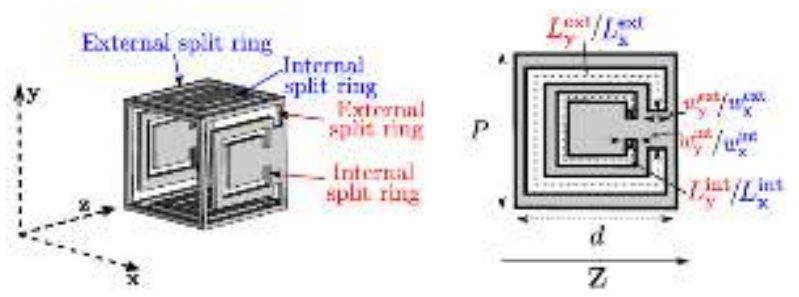

(a)
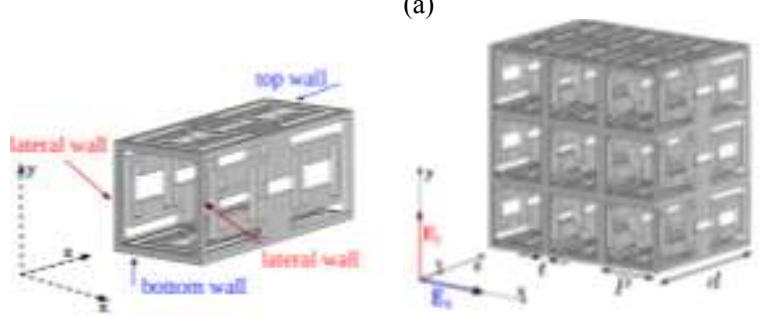

(b)

Fig. 3. 3D unit-cells based on a section of square waveguide perforated with resonators in the lateral and top walls. (a) Cell \#3 accounts with perforations with the shape of split rings; two of them are included in each wall (from [18]). (b) Cell \#4 is perforated with two folded and three $\mathrm{H}$ shaped slots per wall (from [19]).

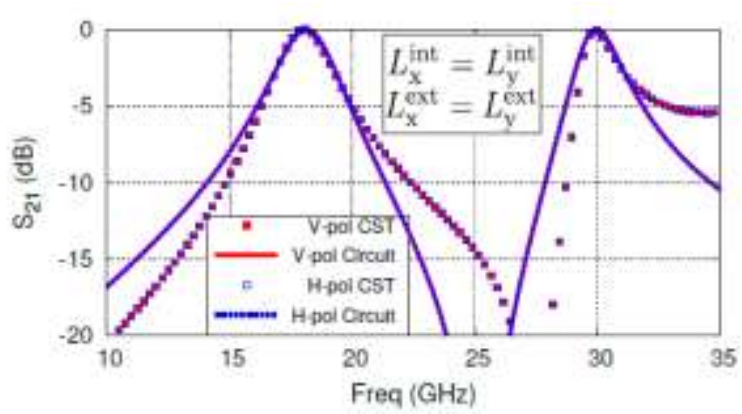

Fig. 4. Design based on Cell \#3 (shown in Fig. 3(a)) implementing dualband dual-polarized frequency selectivity (from [18]).

perforations in the lateral walls. This allows to synthesize multiple bands of transmission, as justified in [18] and [19], since each impinging field excites multiple resonators of different electrical size.

All the cells that have been discussed are physically built from the baseline of a square waveguide. This fact imposes the dispersion of the modes of such a waveguide on the structure performance and their associated narrow-band features. In order to synthesize a broad pass-band in these cells it is necessary to load them with multiple resonators of comparable length in cascade. An alternative solution has been considered which consists of employing an inherently low dispersive waveguide as a baseline to build the cells. In particular, a waveguide supporting the propagation of transverse electro-magnetic waves has been conceived and it is explained in [20]. Such a concept has been employed in the so-called Cell \#5.

\section{SYNTHESIS OF VERSATILE FUNCTIONALITIES}

The results presented in this section illustrate the versatility of the previous cells and the possibility to synthesize diverse RF functionalities.

By employing Cell \#3 it is possible to attain dual-band dual-polarized frequency selectivity. A design implementing such functionality is considered in Fig. 4 which shows the magnitude of the transmission coefficient of the structure 


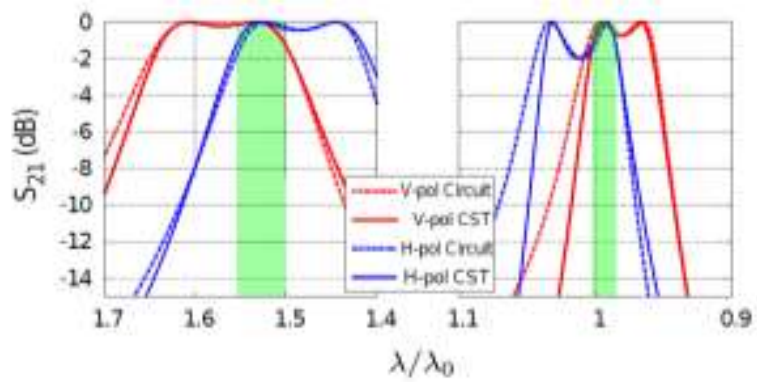

(a)

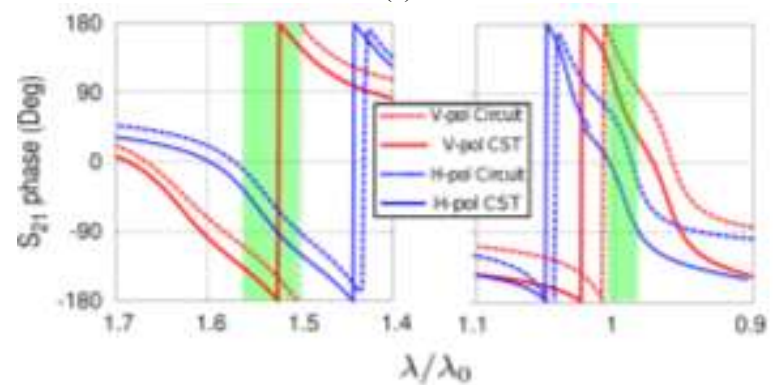

(b)

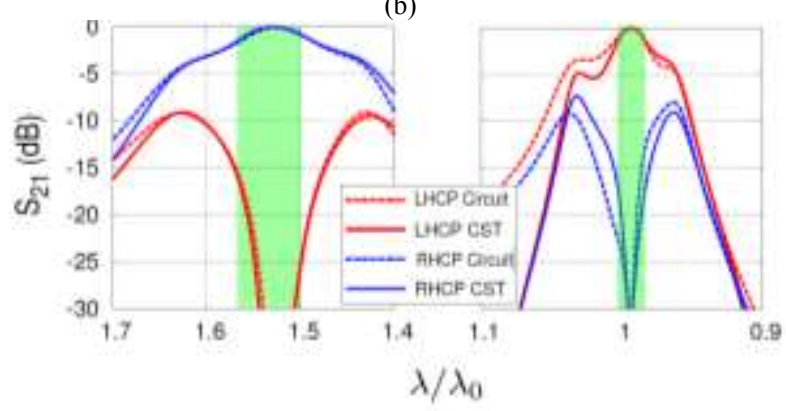

(c)

Fig. 5. Design based on Cell \#4 (shown in Fig. 3(b)) implementing dualband polarization conversion with orthogonal sense of rotation in each band (from [19]). Transmission coefficient when illuminated at normal incidence: (a) magnitude for V- and H.-pol, (b) phase for V-and H-pol, (c) magnitude when illuminated by a $45^{\circ}$-slant field.

when illuminated normally with vertical and horizontal electric fields (V- and H-pol, respectively). Two bands of high transmission can be identified in such figure (centered around $17 \mathrm{GHz}$ and $30 \mathrm{GHz}$ ). The bands for V-pol and H-pol do overlap exactly, since the dimensions of the perforations in the lateral and top walls are identical.

The synthesis of polarization conversion is next considered. By appropriately tuning the pass-band associated to $\mathrm{V}$ - and $\mathrm{H}$ - pol it is possible to attain conversion from linear to circular polarization. Such mechanism is illustrated in Fig. 5, which again considers a dual-band design. Partial overlapping between the pass-bands is patent in the magnitude of the transmission coefficient in Fig. 5(a). Such frequency shift between the bands allows to induce a phase delay between transmitted orthogonal components. In particular, the design has been appropriately conceived to induce $+/-90^{\circ}$-phase shift in each of the pass-bands, as shown in Fig. 5(b). Consequently, the periodic structure allows to convert a $45^{\circ}$-slant electric field into circular polarization of orthogonal sense of rotation in each of the pass-bands, as proven in Fig. 5(c). It should be noted that the linear evolution of the phase behavior that was already anticipated in Fig. 2(b) helps maintaining the polarization conversion within the pass-band.
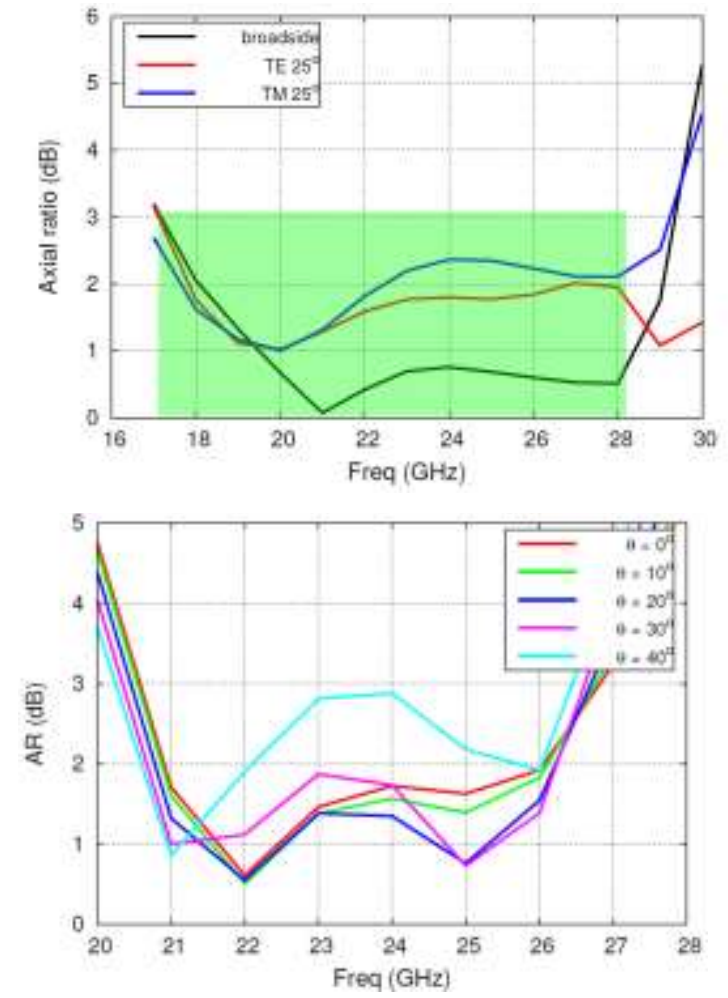

Fig. 6. Design based on Cell \#5 implementing broadband polarization conversion (from [20]). Axial ratio for normal and oblique incidence: (a) design for normal incidence, (b) design implementing the compensation technique for oblique incidence.

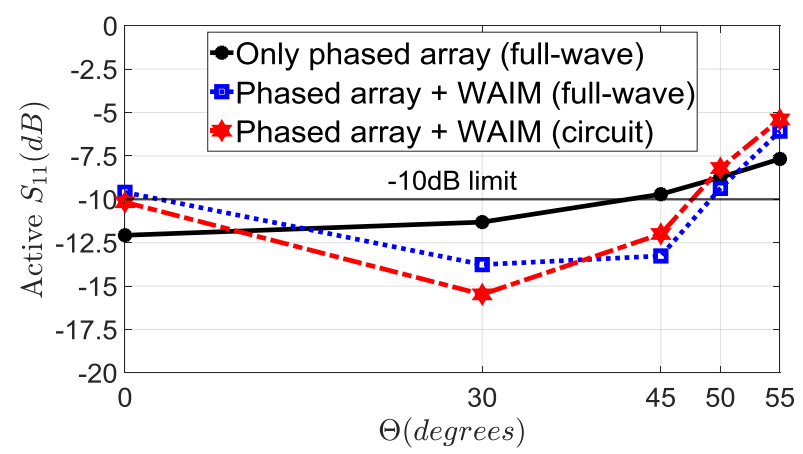

Fig. 7. Active reflection coefficient of an array operating at $18 \mathrm{GHz}$ that scans in the H-plane with an angle $\theta$.

Increasing the bandwidth of previous examples is possible by employing Cell \#5. The performance of two designs in terms of axial ratio (AR) is shown in Fig. 6. On the one hand, Fig. 6(a) shows that a broad bandwidth of $\mathrm{AR}<3 \mathrm{~dB}$ (from approximately $17 \mathrm{GHz}$ up to $29 \mathrm{GHz}$ ) can be attained [20]. On the other hand, Fig. 6(b) shows the performance of a second design that has been conceived applying a technique for incidence compensation. The details of such a technique will be soon be available in a journal publication. As this figure shows, the AR can be improved trading off the performance under normal incidence and the total bandwidth. The results shown here are obtained for TM incidence; similar ones are obtained for TE illumination.

The last example in this section is the design of a WAIM based on the topology of Cell \#5. In this case, the geometry of the unit-cell is appropriately chosen in order to allow to improve the matching (active reflection coefficient) of a phased array. This study is currently on-going, and some 


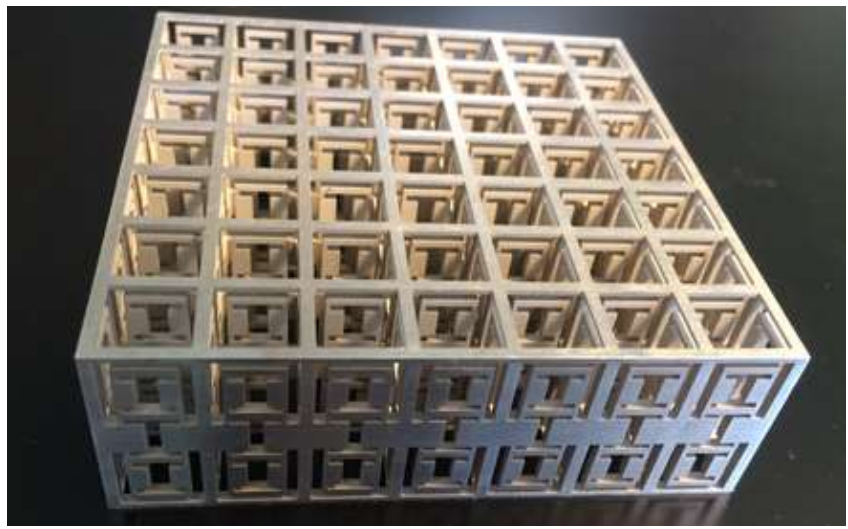

(a)
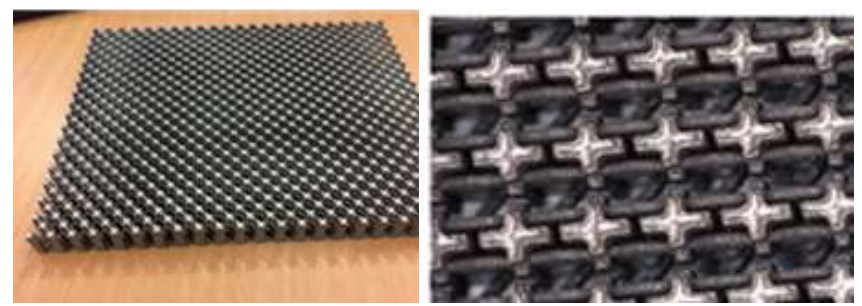

(b)

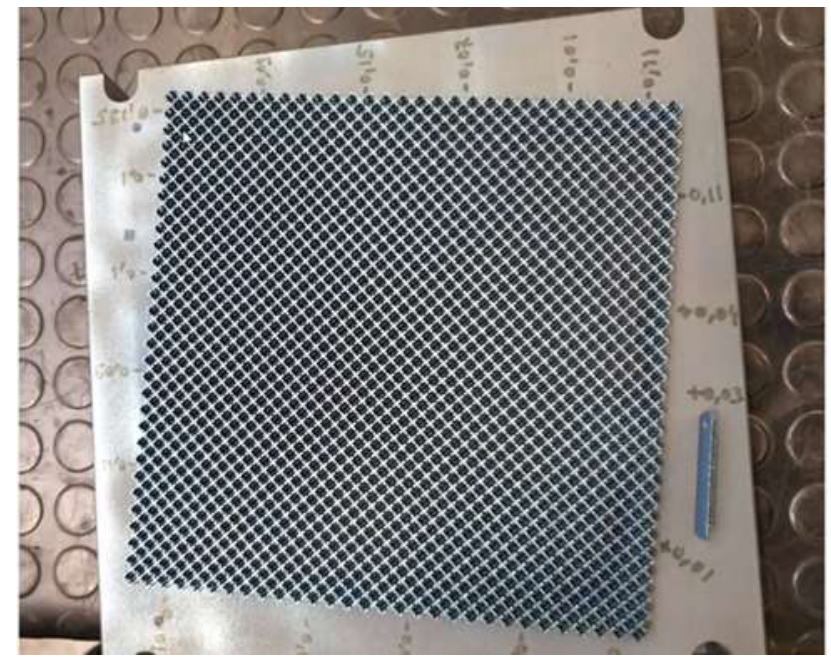

(c)

Fig. 8. Manufactured all-metal polarizing screens: (a) dual-band converter manufactured in Alluminium through EDM, operating in Ku-band, (b) broadband array 3D-printed in Titanium through SLM, operating in $\mathrm{K}$ and Ka-bands, (c) single band converter, 3D-printed in Titanium through SLM, operating in $\mathrm{K}$ band .

preliminary results are shown in Fig. 7 considering H-plane scanning up to $55^{\circ}$. This figure illustrates that by adding the WAIM at the top of the antenna it is possible to enhance its matching (for example when scanning at $30^{\circ}$ and $45^{\circ}$ ). The results do not show yet an improvement of the performances at $55^{\circ}$ of incidence, and they are a bit degraded for broadside radiation. Efforts are currently concentrated towards wider angle enhancement, and also wide frequency bandwidth both for $\mathrm{E}$ and $\mathrm{H}$ planes.

\section{EXPERIMENTAL VALIDATION}

This section presents results associated to the manufacturing and measurement of previous concepts with the objective to provide proof of experimental feasibility.
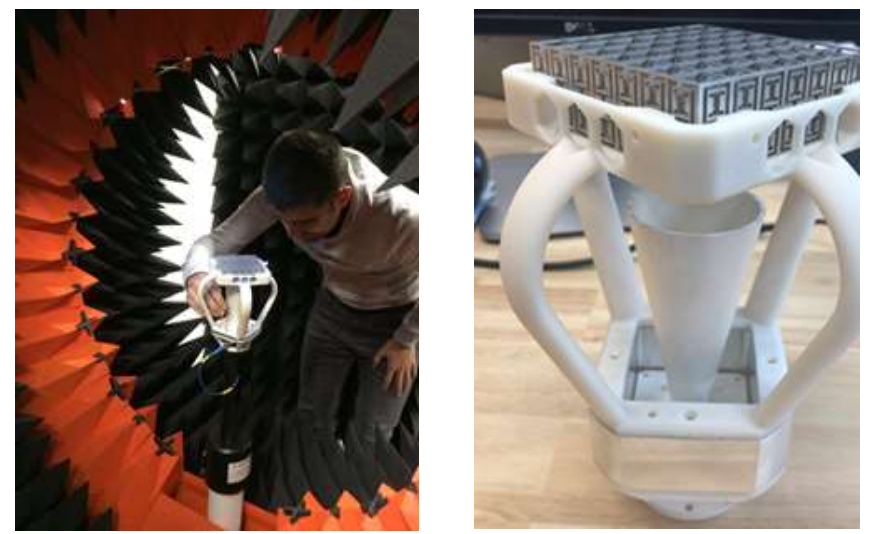

(a)

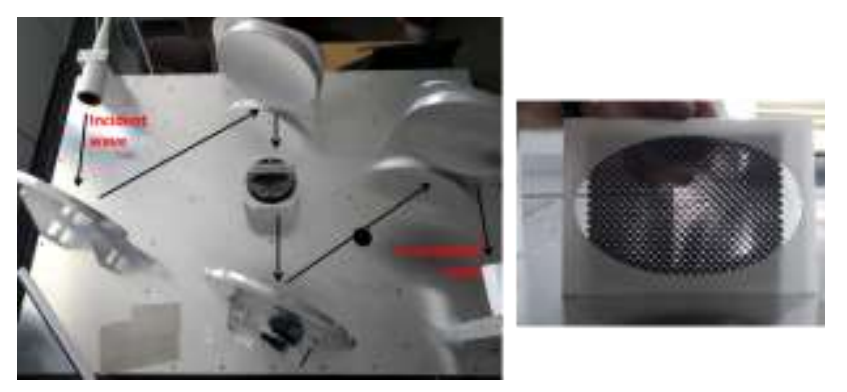

(b)

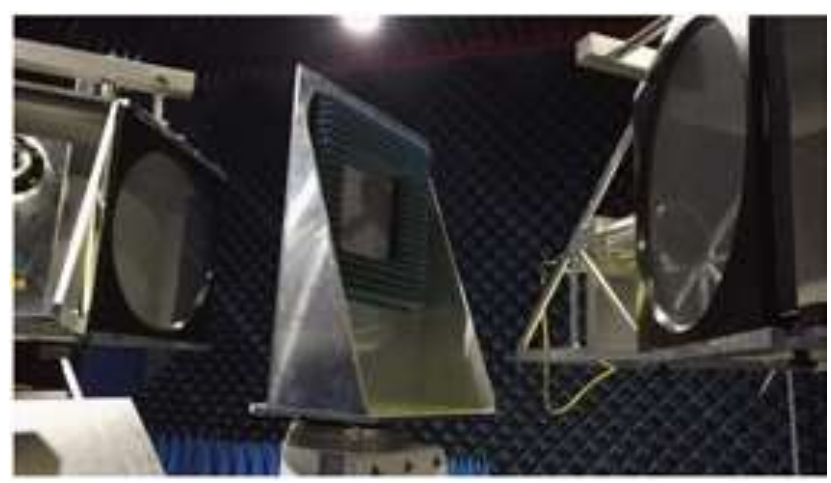

(c)

Fig. 9. Measurement of manufactured prototypes. (a) IETR near-field multi-probe scanner for antenna pattern measurements (MVG StarLab chamber) for sample operating in Ku-band. Setups emulating plane-wave illumination in transmission at: (b) IETR for broadband sample operating in $\mathrm{K}$ and Ka bands, (c) ESA ESTEC for sample operating in Ku-band.

The photographs of three prototypes are shown in Fig. 8. The first one is based on the concept of Cell \#3, and implements the polarization converter which performance is displayed in Fig. 5 in $\mathrm{Ku}$-band. High precision prototyping has been obtained by using Electro Discharge Machining (EDM) on a block of Aluminium. The photograph in Fig. 8(b) is based on the topology of Cell \#5, and it implements broadband polarization conversion covering both $\mathrm{K}$ and $\mathrm{Ka}$ bands. 3D-printing based on Selective Laser Melting (SLM) in Titanium has been employed. Finally, Fig. 8 (c) shows the prototype implementing the compensation technique for oblique incidence at $\mathrm{K}$ band. This example has also been printed based on SLM, and the photograph corresponds to the prototype before been cut from the platform of the 3Dprinter.

Each of the three cases considered in Fig. 8 has been measured employing different setups, which are shown in 


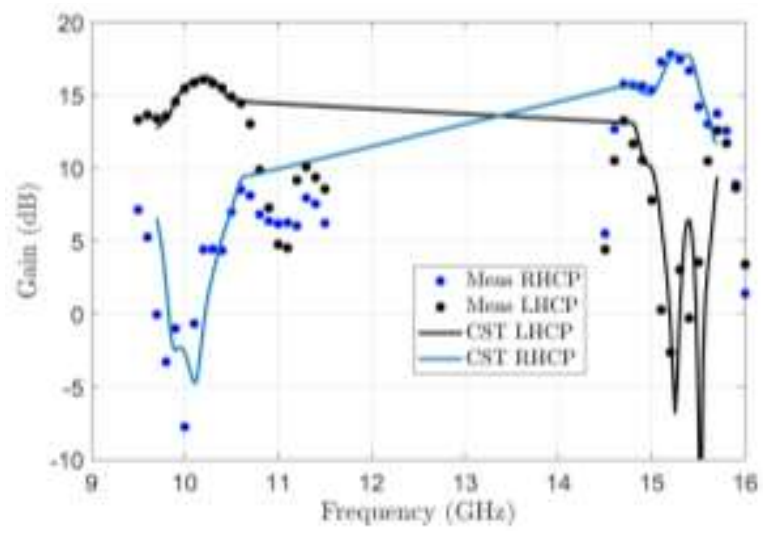

Fig. 10. Measured performance of dual-band polarization converter and comparison with full-wave simulations. The considered feature is the gain of the device under test and the measurement setup shown in Fig. 9(a).

Fig. 9. The first setup is a near field multi-probe chamber which is well suited for measuring the operation of the prototype operating at $\mathrm{Ku}$-band. The polarizer is mounted on top of a linearly polarized horn, and the radiation pattern of the system is measured to assess the polarization conversion. The setups shown in Fig. 9(b) and (c) emulate plane-wave far field illumination of the metallic screens. The first one is employed to measure the prototype of Fig. 8 (b) operating above $18 \mathrm{GHz}$. The second one allows to measure at lower frequencies, and more specifically, the prototype operating in Ku-band of Fig. 8(c).

Finally, Fig. 10 shows the comparison between the results measured in the setup of Fig. 9(a), and corresponding full-wave simulations. As it can be seen, the converter operates in two bands, around $10 \mathrm{GHz}$ and $15 \mathrm{GHz}$. In the lower and upper bands, the screen generates left-handed and right-handed $\mathrm{CP}$, respectively. Note that the horn illuminating the polarizer radiates the same linear polarization in the whole frequency band. The good agreement confirms the validity of the design and the strong potential of the proposed concepts.

\section{ACKNOWLEDGEMENTS}

The authors would like to thank Dr. L. Le Coq and F. Boutet from IETR, for their help in the experimental activities, aswell as T. Pierré from Thales Alenia Space, for his assistance in the printing of the prototype. This work has been supported in part by the Region de Bretagne, Thales Alenia Space, Thales group through their KTD-Hardware, CNES through R\&T funding, the European Union through the European Regional Development Fund, and by the Ministry of Higher Education and Research, Brittany \& Rennes Metropole, through the CPER Project SOPHIE STIC \& Ondes.

\section{REFERENCES}

[1] John C. Vardaxoglou, Frequency Selective Surfaces Analysis and Design, Edt. Taunton Research Studies, 1997.

[2] B. Munk, Frequency Selective Surfaces: Theory and Design, Edt. John Wiley and Sons, 2000.

[3] A. Joyal, and J. J. Laurin, "Design and analysis of a cascade ofcircular polarization frequency selective surface at Ka band," in IEEE Trans. Antennas Propag.,vol. 62, no. 6, pp. 3043-3053, June 2014.
[4] S. H. Abadi, and N. Behdah, "Wideband linear-to-circular polarization converters based on miniaturized-element frequency selectivesurfaces," in IEEE Trans. Antennas Propag.,vol. 64, no. 2, pp. 525-534, Feb. 2016.

[5] E. Magill and H. Wheeler, 'Wide-angle impedance matching of a planar array antenna by a dielectric sheet', IEEE Trans. Antennas Propag., vol. 14, no. 1, pp. 49-53, Jan. 1966.

[6] S. Sajuyigbe, M. Ross, P. Geren, S. A. Cummer, M. H. Tanielian, and D. R. Smith, 'Wide angle impedance matching metamaterials for waveguide-fed phased-array antennas', IET Microw. Antennas Propag., vol. 4, no. 8, p. 1063, 2010.

[7] E. Gandini et al., 'A Dielectric Dome Antenna With Reduced Profile and Wide Scanning Capability', IEEE Trans. Antennas Propag., vol. 69, no. 2, pp. 747-759, Feb. 2021.

[8] M. Ehrenberg, S. E. Sarma, and B. Wu, "A three-dimensional self supporting low-loss microwave lens with a negative refractive index," in journal Applied Physics,vol. 112, pp. 073114 1-4, July 2012

[9] C. Pelletti, G Bianconi, R. Mittra and Z. Shen, "Frequency selective surface with wideband quasi-elliptic bandpass response," in ElectronicLetters,vol. 49, no. 17, pp. 1052-1053, Aug. 2013.

[10] B. Sanz-Izquierdo, and E. A. Parker, "3D printing of elements infrequency selective arrays," inIEEE Trans. Antennas Propag.,vol. 62, no. 12, pp. 6060-6066, Dec. 2014.

[11] A. A. Omar, and Z. Shen, "Multiband high-order bandstop 3D frequency-selective structures," inIEEE Trans. Antennas Propag.,vol.64, no. 6, pp. 2217-2226, June 2016.

[12] M. L. N. Chen, L. J. Jian, W. E. I. Sha, W. C. H. Choy, and T. Itoh, "Polarization control by using anisotropic 3-d chiral structure," IEEE Trans. Antennas Propag., vol. 64, no. 11, pp. 4687-4694, Nov. 2016.

[13] K. X. Wang, and H. Wong, "A wideband millimeter-wave circularly polarized antenna with 3D printed polarizer," in IEEE Antennas WirelessPropag. Lett.,vol. 65, no. 3, pp. 1038-1046, March 2017.

[14] J. Zhu, W Tang, C. Wang, C. Huang, and Y. Shi, "Dual-polarized bandpass frequency-selective surface with quasi-elliptic response based on square coaxial waveguide," in IEEE Trans. Antennas Propag.,vol.66, no. 3, pp. 1331-1339, March 2018.

[15] D. Z. Zhu, M. D. Gregory, P. L. Werner and D. H. Werner, "Fabrication and characterization of multiband polarization independent 3-D-printed frequency selective structures with ultrawide fields of view," in IEEE Trans. Antennas Propag.,vol. 66, no. 11, pp. 6096-6105, Nov. 2018.

[16] C. Molero, and M. García-Vigueras, "Circuit modeling of 3-D cells todesign versatile full-metal polarizers," in IEEE Trans. microw. TheoryTechn.,vol. 67, no. 4, pp. 1357-1369, March 2019.

[17] Deng, Y. Yu, Z. Shen, and Z. N. Chen, "Design of 3-D multi-layer ferrite-loaded frequency-selective rasorbers with wide absorption bands," inIEEE Trans. Antennas Propag.,vol. 67, no. 1, pp. 108-117, June 2019.

[18] C. Molero, E. Menargues, T. Debogovic and M. García-Vigueras, "Circuit Modelling of Metallic Dual-Band Dual-Polarized FSS," 2019 49th European Microwave Conference (EuMC), 2019, pp. 770-773.

[19] C. Molero, E. Menargues, and M. García-Vigueras, "All metal 3D frequency-selective surface with versatile dual-band polarization conversion," in IEEE Trans. Antennas Propag.,vol. 68, no. 7, pp. 5431-5441, July 2020.

[20] C. Molero, H. Legay, T. Pierré and M. García-Vigueras, "Broadband 3D-Printed Polarizer based on Metallic Transverse Electro-Magnetic Unit-Cells," under review. 